\title{
The Association between Change in Physical Activity and Weight during Adolescence
}

\author{
Jill L Kaar ${ }^{1^{*}}$, Esther van Sluijs ${ }^{2}$, Stephen J Sharp ${ }^{2}$, Elizabeth F Nagle ${ }^{3}$, Robert J Robertson ${ }^{3}$ and Deborah J Aaron ${ }^{3}$ \\ ${ }^{1}$ Department of Pediatrics, University of Colorado School of Medicine, Aurora, CO, USA \\ ${ }^{2}$ Medical Research Council Epidemiology Unit, University of Cambridge, Cambridge, UK \\ ${ }^{3}$ Department of Health and Physical Activity, University of Pittsburgh, Pittsburgh, PA, USA
}

*Corresponding author: Jill L Kaar, Department of Pediatrics - Section of Nutrition, University of Colorado School of Medicine, 12631 E. $17^{\text {th }}$ Avenue, Campus Box F561 Aurora, CO 80045, USA, Tel: 303-724-5745; E-mail: jill.kaar@ucdenver.edu

Received date: July 15, 2015, Accepted date: August 10, 2015, Published date: August 17, 2015

Copyright: 2015 @ Kaar $\mathrm{JL}$, et al. This is an open-access article distributed under the terms of the Creative Commons Attribution License, which permits unrestricted use, distribution, and reproduction in any medium, provided the original author and source are credited

\begin{abstract}
Objective: To investigate the association between annual change in physical activity and subsequent annual change in weight status in adolescents over a 4 year period.
\end{abstract}

Design: Longitudinal study design with annual data collection over 4 years. Setting: Suburban school district in Pittsburgh, PA. Participants: 1245 adolescents aged 11-16 years. Main outcome measures: Physical activity and body mass index (BMI) percentile. Analysis: Generalized estimating equation (GEE).

Results: 994 participants (53\% male) were included in the analyses. The longitudinal associations between changes in physical activity and BMI\% were mostly small and non-significant. However, compared with those who did not change their physical activity, a large annual increase in physical activity (>10 hr/wk) was associated with a significant increase in BMI\%. Results were broadly similar for total and vigorous physical activity, boys and girls and for healthy and unhealthy (>85th percentile) BMI\%.

Conclusions and Implications: The role of physical activity in the development of obesity during adolescence therefore remains unclear. Further work is needed to elucidate the role of physical activity in the prevention of obesity.

Keywords: Adolescents; Longitudinal survey; Physical activity; Obesity; GEE

\section{Introduction}

In 2014, the National Health and Nutrition Examination Survey (NHANES) reported that $34.5 \%$ of adolescents aged $12-19$ years were overweight or obese [1]. Obese adolescents are at high risk for many medical complications [2] that were previously found primarily among adults including; hypertension [3], hyperlipidemia [4], diabetes [4,5] and sleep apnea [6]. Obesity throughout adolescence may also have detrimental psychosocial consequences such as exposure to teasing or ridicule about weight issues [2,7].

Factors which are associated with the increase of childhood and adolescent obesity include parental weight status, birth weight, poor diet and a lack of physical activity [2,8]. Engaging in physical activity has been associated with health benefits in children and adolescents including improved overall weight control [9-11] and psychological [12] and general well-being [13].

The identification of mechanisms that may attenuate the progression of abnormal weight gain throughout adolescence is needed to move both individual and population based interventions forward [2]. One such mechanism is the association between changes in physical activity and changes in weight status throughout adolescence.
A recent systematic review concluded that physical activity during adolescence is protective against obesity; however, this conclusion was based mainly on cross sectional studies as a very limited number of longitudinal studies have been conducted [14]. Of these, some were able to show significant evidence that declines in physical activity during adolescence were associated with increases in body weight [15-18].

The evidence however is still equivocal as others have reported no significant relationship [19,20] and furthermore, Kettaneh et al. [21] found the association to be dependent on gender as a significant relationship was found in girls and no association among boys.

The present analysis adds to the current literature as it investigates how changes in physical activity may affect weight status over a four year time period using a large diverse sample of adolescents. The primary objective of this study was to investigate the association between annual change in physical activity and subsequent annual change in weight status (i.e., BMI percentile) in adolescents over a 4 year period.

A secondary objective was to identify gender and baseline weight status differences in the relationship between physical activity and weight gain (i.e., BMI percentile). We hypothesize that a decrease in physical activity during adolescence will result in an increase in weight gain (i.e., BMI percentile) during this time. 


\section{Methods}

\section{Study sample}

Participants for this longitudinal study were part of the Adolescent Injury Control Study (AICS), a 4 year National Institute of Health funded study. AICS aimed to examine the contribution of sport and recreational physical activity to all-cause injury incidence in adolescents $[22,23]$. The AICS included $7^{\text {th }}, 8^{\text {th }}$, and $9^{\text {th }}$ grade students (aged between 11 and 16 years) recruited from a local suburban school district in Pittsburgh, Pennsylvania (USA) during August of 1989. Students and parents signed an informed consent, approved by the University of Pittsburgh Institutional Review Board. There were 1245 participants ( 643 boys and 602 girls) in the study, and the follow-up period was four years. In the present analyses, students who were older than 16 years of age at baseline $(n=40)$ were excluded due to the inability to categorize their BMI over the whole 4 year follow-up period of the study using the standard paediatric BMI percentile categories from the Centers for Disease Control and Prevention (CDC), which only apply up to 18 years of age. Due to the low number of Hispanic $(n=7)$ and Asian $(n=8)$ students as well as students reporting "other" race/ethnic group $(\mathrm{n}=21)$, only Caucasians and African Americans were included in the present analyses. There are known racial/ethnic differences in physical activity patterns and the prevalence of obesity [24] and we therefore felt it was not possible to combine these students (Hispanic, Asian, Other Race/Ethnicity) into a single minority group. Those who reported more than $168 \mathrm{hrs} / \mathrm{wk}$ of physical activity at any time point $(\mathrm{n}=1)$ were also excluded. Those who did not have at least one valid value simultaneously for the outcome and exposure were excluded $(n=168)$. Finally, those who did not have body composition data at baseline were excluded $(n=6)$ as baseline BMI\% was included in our model. Data from 994 students were therefore included in our analyses.

\section{Data collection}

Physical activity: During the spring term of each school year (1990, 1991, 1992, and 1993), trained research staff administered the Modifiable Activity Questionnaire for Adolescents (MAQ) during physical education classes [25]. The MAQ assesses physical activity in the past year and has been shown to be both reliable and valid in measuring physical activity in an adolescent population [26]. In order for a student to report an activity, they had to participate in the activity a minimum of ten times over the past year.

Each student was provided a list of 26 activities (i.e., aerobics, band/ drill team, basketball, etc) to choose from along with blank spaces to add additional activities not listed. The frequency and duration of each activity listed was also recorded. This questionnaire was used to estimate the total hours per week (hrs/wk) of overall leisure time activity ( $\geq 3$ Metabolic equivalent (MET)) in the past year. In addition, total hours per week of vigorous activity (defined as $\geq 6 \mathrm{MET}$ ) was estimated for each year.

Weight status: At the time of physical activity measurement, a calibrated balance scale was used to measure weight and a wall mounted measuring tape was used to measure height. Epi Info (a computer based program provided by the $\mathrm{CDC}$ ) was used to calculate each participant's body mass index (BMI) $\left(\mathrm{kg} / \mathrm{m}^{2}\right)$ and BMI percentile [27]. Adolescents were categorized as "At Risk for Overweight" if their BMI percentile was between the $85-95^{\text {th }}$ percentile and "Overweight" if their BMI percentile was greater than the $95^{\text {th }}$ percentile.
Definition of outcomes and exposures: For each individual, the outcome variable was defined as change in BMI percentile from either 1) 1990 to 1991 , 2) 1991 to 1992 , or 3) 1992 to 1993 . The exposure was defined as change in physical activity from either 1) 1989 to 1990, 2) 1990 to 1991, or 3) 1991 to 1992. This assumed that physical activity reported in a particular year (e.g., 1990), reflects level of physical activity during the previous year (e.g., 1989). The change in physical activity exposure variable was then categorized into 7 groups: 1) large decrease (>10 hrs/wk); 2) moderate decrease (5-9.99 hrs/wk); 3) small decrease (2-4.99 hrs/wk); 4) no change ( $\pm 1.99 \mathrm{hrs} /$ week); 5) small increase (2-4.99hrs/wk); 6) moderate increase (5-9.99 hrs/wk); and 7) large increase (>10 hrs/wk).

Sociodemographic data: Socioeconomic status (SES) was determined according to percentage of the population below the poverty level of the neighborhood where the child resided. Each neighborhood's SES was classified as high (less than $10 \%$ below poverty level), middle (10-20\% below poverty level), or low (greater than $20 \%$ below poverty level) [28].

\section{Statistical analysis}

The longitudinal association between change in physical activity and change in BMI percentile was modelled using a generalized estimating equation (GEE) assuming an exchangeable correlation structure, and with robust standard errors (using STATA version 10.1) (StataCorp, College Station, TX).

The model included sex, baseline BMI percentile (i.e., BMI percentile at the start of the year in question), and age. Ethnicity and SES were also considered as potential confounders, but their inclusion in the model made almost no differences to the estimated association, so they were therefore not included in the final model. The analysis was performed using the overall sample and also within subgroups defined by gender and weight status (healthy weight defined as $5-85^{\text {th }}$ BMI percentile and unhealthy weight defined as $>85^{\text {th }}$ BMI percentile). A similar analysis was performed using change in vigorous physical activity as the exposure.

\section{Results}

Baseline characteristics of the study sample are described in Table 1. Overall, the sample included 994 adolescents with a mean age of 13.5 $( \pm 1.0)$ years. The sample included a larger number of males $(52.8 \%)$, those categorized as Caucasian (77.9\%), and of middle SES (53.6\%). Overall the sample was found to be of a healthy weight (defined as a BMI percentile of $5-85 \%$ ) while $16.3 \%$ were overweight (BMI percentile $>85-95 \%$ ), and $10.3 \%$ were categorized as obese (BMI percentile $>95 \%$ ).

The median physical activity of the sample was $13.3 \mathrm{hrs} / \mathrm{wk}$ (IQR 5.3 to 27.2 ) and $7.0 \mathrm{hrs} / \mathrm{wk}$ (IQR 2.3 to 16.4) of vigorous activity. The 174 participants excluded from the analysis based on lack of physical activity and weight status data were found to be significantly more likely to be girls and Caucasian compared with participants included in the analyses sample. Table 2 illustrates the distribution of the sample within each change in physical activity category over each time period (Figures 1 and 2). 
Citation: Kaar JL, Sluijs EV, Sharp SJ, Nagle EF, Robertson RJ, et al. (2015) The Association between Change in Physical Activity and Weight during Adolescence. J Child Adolesc Behav 3: 233. doi:10.4172/2375-4494.1000233

Page 3 of 7

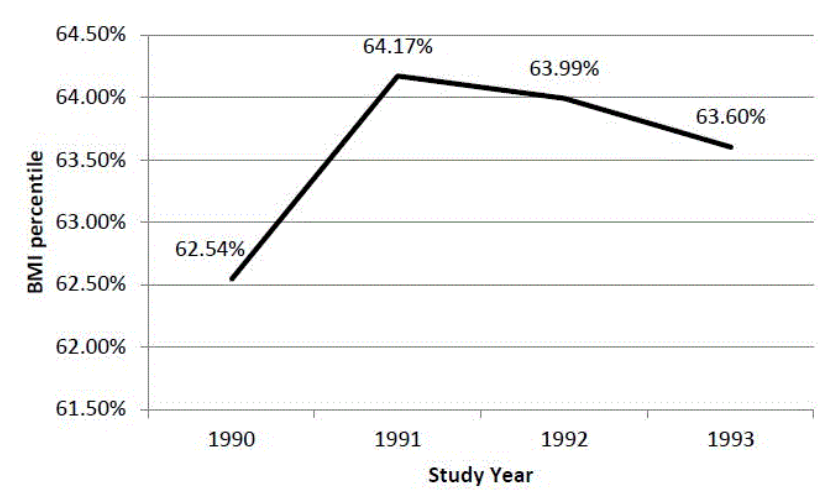

Figure 1: BMI percentile by Study Year.

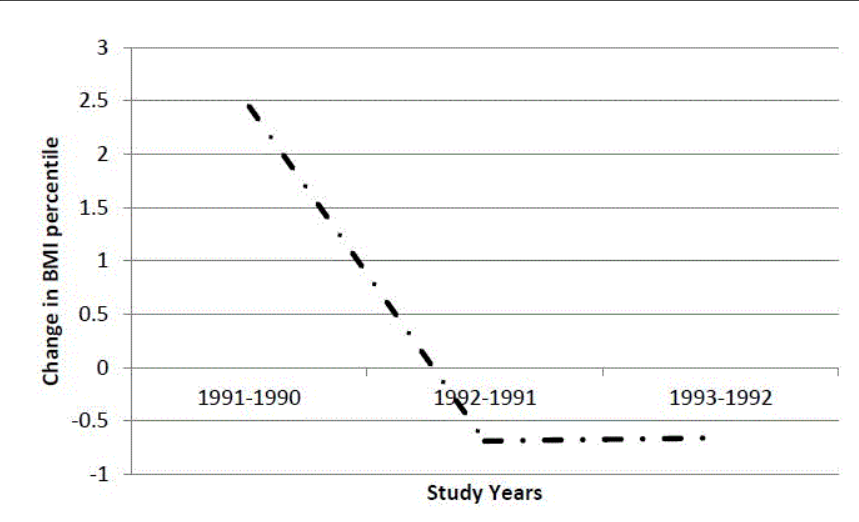

Figure 2: Change in BMI percentile by Study Year.

\begin{tabular}{|c|c|c|c|}
\hline Characteristics & Total & Boys & Girls \\
\hline Gender & & Percentage (\%) & \\
\hline Boys & 52.8 & & \\
\hline Girls & 47.2 & & \\
\hline \multicolumn{4}{|l|}{ Race } \\
\hline Caucasian & 77.9 & 78.5 & 77.2 \\
\hline African American & 22.1 & 21.5 & 22.8 \\
\hline \multicolumn{4}{|l|}{ SES } \\
\hline Low & 17.7 & 30.7 & 26.4 \\
\hline Middle & 53.6 & 51.8 & 55.7 \\
\hline High & 28.7 & 17.5 & 17.9 \\
\hline Percent Overweight ${ }^{*}$ & 10.3 & 14.1 & 18.8 \\
\hline \multirow[t]{2}{*}{ Percent At Risk for Overweight* } & 16.3 & 12.4 & 7.9 \\
\hline & & Mean (SD) & \\
\hline Age (years) & $13.5(1.0)$ & $13.6(1.0)$. & $13.5(1.0)$ \\
\hline Height (cm) & $160.7(8.9)$ & $163.4(9.7)$ & $157.7(6.5)$ \\
\hline Weight (kg) & $57.5(13.7)$ & $59.0(14.7)$ & $55.8(12.2)$ \\
\hline BMI (kg/m2) & $21.4(4.2)$ & $21.2(4.2)$ & $21.6(4.3)$ \\
\hline \multirow[t]{2}{*}{ BMI percent (\%) } & $61.4(27.6)$ & $59.5(29.0)$ & $63.5(25.9)$ \\
\hline & & Median (IQR) & \\
\hline Physical Activity (hrs/wk) * & $13.3(5.3,27.2)$ & $23.1(12.1,37.5)$ & $6.9(3.1,13.6)$ \\
\hline Vigorous Physical Activity (hrs/wk) * & $7.0(2.3,16.4)$ & $12.5(5.3,23.6)$ & $3.1(0.8,7.8)$ \\
\hline
\end{tabular}

Table 1: Baseline Characteristics of Participants used in Analysis ( $\mathrm{N}=994)$. 
Citation: Kaar JL, Sluijs EV, Sharp SJ, Nagle EF, Robertson RJ, et al. (2015) The Association between Change in Physical Activity and Weight during Adolescence. J Child Adolesc Behav 3: 233. doi:10.4172/2375-4494.1000233

Page 4 of 7

\begin{tabular}{|c|c|c|c|c|c|c|c|c|c|}
\hline & \multicolumn{3}{|c|}{1989 to 1990} & \multicolumn{3}{|c|}{1990 to 1991} & \multicolumn{3}{|c|}{1991 to 1992} \\
\hline & & $N=954$ & & & $\mathrm{~N}=\mathbf{8 8 2}$ & & & $N=730$ & \\
\hline & $T$ & B & G & $T$ & B & G & $T$ & B & G \\
\hline \multicolumn{10}{|l|}{ Physical Activity } \\
\hline Large decrease $(\geq 10 \mathrm{~h} / \mathrm{wk})$ & 24.6 & 35.5 & 12.7 & 21.9 & 27.8 & 15.2 & 17.9 & 24.3 & 10.6 \\
\hline Moderate decrease (5-9.99 h/wk) & 9.1 & 8.6 & 9.6 & 13.4 & 14.3 & 12.4 & 16 & 17.7 & 14.1 \\
\hline Small decrease $(2-4.99 \mathrm{~h} / \mathrm{wk})$ & 10.8 & 7.6 & 14.2 & 11.9 & 11.3 & 12.6 & 13.4 & 9.7 & 17.7 \\
\hline No change $( \pm 1.99 \mathrm{~h} / \mathrm{wk})$ & 18.5 & 12.4 & 25.2 & 22.6 & 15 & 31.2 & 24.8 & 20.5 & 29.7 \\
\hline Small increase (2-4.99 h/wk) & 8.8 & 6.2 & 11.6 & 10.3 & 6.4 & 14.5 & 10.4 & 7.2 & 14.1 \\
\hline Moderate increase $(5-9.99 \mathrm{~h} / \mathrm{wk})$ & 11.1 & 10 & 12.3 & 10.6 & 12.8 & 8.1 & 8.3 & 9.2 & 7.4 \\
\hline Large increase $(\geq 10 \mathrm{~h} / \mathrm{wk})$ & 17.2 & 19.8 & 14.4 & 9.4 & 12.4 & 6 & 9.2 & 11.5 & 6.5 \\
\hline \multicolumn{10}{|l|}{ Vigorous Physical Activity } \\
\hline Large decrease ( $\geq 10 \mathrm{~h} / \mathrm{wk})$ & 16.8 & 25 & 7.9 & 16.3 & 22.9 & 9.1 & 13.1 & 18.9 & 6.5 \\
\hline Moderate decrease (5-9.99 h/wk) & 10.1 & 11.2 & 9 & 11.5 & 13.7 & 9.1 & 10.3 & 11 & 9.4 \\
\hline Small decrease $(2-4.99 \mathrm{~h} / \mathrm{wk})$ & 12.2 & 9.6 & 15.1 & 15.2 & 12.6 & 18.1 & 14 & 14.3 & 13.5 \\
\hline No change $( \pm 1.99 \mathrm{~h} / \mathrm{wk})$ & 28 & 16.4 & 40.7 & 34.2 & 22.2 & 47.6 & 43.6 & 29.2 & 60.3 \\
\hline Small increase $(2-4.99 \mathrm{~h} / \mathrm{wk})$ & 9.9 & 8.2 & 11.8 & 9.6 & 9.4 & 9.8 & 8.9 & 11.5 & 5.9 \\
\hline Moderate increase (5-9.99 h/wk) & 11.2 & 13 & 9.2 & 6.5 & 9.8 & 2.9 & 5.2 & 7.2 & 2.9 \\
\hline Large increase ( $\geq 10 \mathrm{~h} / \mathrm{wk})$ & 11.8 & 16.8 & 6.4 & 6.6 & 9.4 & 3.6 & 4.9 & 7.9 & 1.5 \\
\hline
\end{tabular}

Table 2: Percentage of Participants in Categories of Change in Total Physical Activity and Vigorous Physical Activity within each Measurement Period.

Table 3 shows the longitudinal associations between change in physical activity and subsequent change in BMI percentile. The associations were mostly small and non-significant; however, compared with those who did not change their physical activity, an increase in physical activity greater than $10 \mathrm{hrs} / \mathrm{wk}$ from one year to the next was associated with a significant increase in subsequent change in BMI percentile $(\mathrm{p}<0.001)$. This association was also observed consistently among girls $(\mathrm{p}<0.01)$, boys $(\mathrm{p}<0.01)$, and healthy weight adolescents $(\mathrm{p}<0.001)$.

Table 4 shows the longitudinal associations between change in vigorous physical activity and subsequent change in BMI percentile. The results were similar to those where overall physical activity was the exposure.

\begin{tabular}{|c|c|c|c|c|c|c|c|c|c|c|}
\hline & \multicolumn{2}{|c|}{ Overall } & \multicolumn{2}{|c|}{ Boys } & \multicolumn{2}{|c|}{ Girls } & \multicolumn{2}{|c|}{ Healthy BMI\% } & \multicolumn{2}{|c|}{ Unhealthy BMI\% } \\
\hline & \multicolumn{2}{|c|}{ obs $=2505$} & \multicolumn{2}{|c|}{ obs $=1319$} & \multicolumn{2}{|c|}{ obs $=1186$} & \multicolumn{2}{|c|}{ obs=1815 } & \multicolumn{2}{|c|}{ obs $=674$} \\
\hline PA level & $\beta$ & $95 \% \mathrm{Cl}$ & $\beta$ & $95 \% \mathrm{Cl}$ & $\beta$ & $95 \% \mathrm{Cl}$ & $\beta$ & $95 \% \mathrm{Cl}$ & $\beta$ & $95 \% \mathrm{Cl}$ \\
\hline $\begin{array}{l}\text { Large decrease } \\
\quad(\geq 10 \mathrm{~h} / \mathrm{wk})\end{array}$ & 0.5 & $-0.8,1.7$ & -0.1 & $-1.9,1.6$ & 1.1 & $-1.0,3.1$ & 0.6 & $-1.0,2.2$ & -0.0 & $-1.8,1.8$ \\
\hline $\begin{array}{l}\text { Moderate decrease } \\
(5-9.99 \mathrm{~h} / \mathrm{wk})\end{array}$ & 0.2 & $-1.4,1.7$ & -0.7 & $-2.9,1.4$ & 1.1 & $-1.2,3.3$ & -0.1 & $-2.1,1.9$ & 0.7 & $-1.1,2.5$ \\
\hline $\begin{array}{c}\text { Small decrease }(2-4.99 \\
\mathrm{h} / \mathrm{wk})\end{array}$ & 0.2 & $-1.3,1.7$ & 0.1 & $-2.2,2.4$ & 0.2 & $-1.8,2.1$ & -0.2 & $-2.1,1.7$ & 0.3 & $-1.8,2.5$ \\
\hline No change $( \pm 1.99 \mathrm{~h} / \mathrm{wk})$ & 0 & & 0 & & 0 & & 0 & & 0 & \\
\hline
\end{tabular}


Page 5 of 7

\begin{tabular}{|c|c|c|c|c|c|c|c|c|c|c|}
\hline $\begin{array}{c}\text { Small increase (2-4.99 } \\
\mathrm{h} / \mathrm{wk})\end{array}$ & 0.9 & $-0.6,2.4$ & -0.8 & $-3.5,2.0$ & 1.8 & $-0.1,3.6$ & 0.7 & $-1.1,2.6$ & 0.8 & $-1.9,3.5$ \\
\hline $\begin{array}{c}\text { Moderate increase } \\
(5-9.99 \mathrm{~h} / \mathrm{wk})\end{array}$ & 0.5 & $-1.1,2.0$ & 0.4 & $-1.8,2.5$ & 0.3 & $-2.0,2.6$ & 0.2 & $-1.9,2.3$ & 0.9 & $-0.9,2.7$ \\
\hline $\begin{array}{c}\text { Large increase } \\
(\geq 10 \mathrm{~h} / \mathrm{wk})\end{array}$ & $3.1^{* *}$ & $1.5,4.7$ & $2.6^{*}$ & $0.5,4.7$ & $3.3^{*}$ & $0.7,5.8$ & $3.6^{* *}$ & $1.6,5.7$ & 1.4 & $-0.4,3.3$ \\
\hline $\begin{array}{l}\text { obs = number of observations, as each individual had one or more observations } \\
\text { Healthy weight defined as 5-85th BMI percentile; Unhealthy weight >85th BMI percentile All analyses adjusted for age, sex, and BMI percentile at baseline year. } \\
{ }^{*} \mathrm{p}<0.01 ;{ }^{* *} \mathrm{p}<0.001\end{array}$ \\
\hline
\end{tabular}

Table 3: Longitudinal Association Between Yearly change in Physical Activity and Subsequent Change in BMI Percentile in 994 Adolescents over Three Years.

\begin{tabular}{|c|c|c|c|c|c|c|c|c|c|c|}
\hline & \multirow{2}{*}{\multicolumn{2}{|c|}{$\begin{array}{c}\text { Overall } \\
\text { obs=2505 }\end{array}$}} & \multirow{2}{*}{\multicolumn{2}{|c|}{$\begin{array}{c}\text { Boys } \\
\text { obs=1319 }\end{array}$}} & \multirow{2}{*}{\multicolumn{2}{|c|}{$\begin{array}{c}\text { Girls } \\
\text { obs=1186 }\end{array}$}} & \multirow{2}{*}{\multicolumn{2}{|c|}{$\begin{array}{c}\text { Healthy BMI\% } \\
\text { obs=1815 }\end{array}$}} & \multirow{2}{*}{\multicolumn{2}{|c|}{$\begin{array}{c}\text { Unhealthy BMI\% } \\
\text { obs }=674\end{array}$}} \\
\hline & & & & & & & & & & \\
\hline Vigorous PA level & $\beta$ & $95 \% \mathrm{Cl}$ & $\beta$ & $95 \% \mathrm{Cl}$ & $\beta$ & $95 \% \mathrm{Cl}$ & $\beta$ & $95 \% \mathrm{Cl}$ & $\beta$ & $95 \% \mathrm{Cl}$ \\
\hline Large decrease $(\geq 10 \mathrm{~h} / \mathrm{wk})$ & 0.4 & $-0.9,1.7$ & 0.4 & $-1.2,2.1$ & 0.0 & $-2.5,2.5$ & 0.2 & $-1.5,1.9$ & 0.7 & $-0.9,2.3$ \\
\hline $\begin{array}{l}\text { Moderate decrease (5-9.99 } \\
\mathrm{h} / \mathrm{wk})\end{array}$ & 0.5 & $-1.1,2.0$ & 0.4 & $-1.8,2.5$ & 0.5 & $-1.8,2.9$ & 0.8 & $-1.2,2.7$ & -0.3 & $-2.4,1.8$ \\
\hline $\begin{array}{c}\text { Small decrease (2-4.99 } \\
\mathrm{h} / \mathrm{wk})\end{array}$ & 0.8 & $-0.4,2.0$ & 0.1 & $-1.8,2.0$ & 1.4 & $-0.3,3.0$ & 1.0 & $-0.6,2.6$ & 0.3 & $-1.2,1.8$ \\
\hline No change $( \pm 1.99 \mathrm{~h} / \mathrm{wk})$ & 0 & & 0 & & 0 & & 0 & & 0 & \\
\hline $\begin{array}{c}\text { Small increase }(2-4.99 \\
\mathrm{h} / \mathrm{wk})\end{array}$ & 0.3 & $-1.2,1.7$ & 0.6 & $-1.5,2.6$ & -0.1 & $-2.2,1.9$ & -0.0 & $-1.9,1.8$ & 1.6 & $-0.4,3.5$ \\
\hline $\begin{array}{l}\text { Moderate increase (5-9.99 } \\
\mathrm{h} / \mathrm{wk})\end{array}$ & 1.5 & $-0.4,3.3$ & 1.1 & $-0.9,3.1$ & 2.2 & $-1.7,6.1$ & 1.9 & $-0.5,4.4$ & 0.8 & $-1.2,2.8$ \\
\hline Large increase ( $\geq 10 \mathrm{~h} / \mathrm{wk})$ & $2.5^{\star \star}$ & $0.9,4.2$ & $2.7^{\star \star}$ & $0.6,4.8$ & 1.6 & $-0.7,4.0$ & $2.6^{*}$ & $0.4,4.7$ & $2.1^{* *}$ & $0.6,3.6$ \\
\hline $\begin{array}{l}\text { obs }=\text { number of observations } \\
\text { Healthy weight defined as } 5-8 \\
{ }^{*} p<0.05 ;{ }^{* *} p<0.01 ;{ }^{* \star *} p<0.001\end{array}$ & $\begin{array}{l}\text { as each } \\
\text { th BMI } p\end{array}$ & $\begin{array}{l}\text { vidual had } \\
\text { ntile; Unh }\end{array}$ & $\begin{array}{l}\text { or more } \\
\text { ny weigh }\end{array}$ & $\begin{array}{l}\text { servations } \\
\text { 5th BMI p }\end{array}$ & entile $A$ & nalyses ac & ed for & sex, and & ercentil & ine year. \\
\hline
\end{tabular}

Table 4: Longitudinal Association between Yearly Change in Vigorous Physical Activity and Subsequent Change in BMI Percentile in 994 Adolescents over Three Years.

\section{Discussion}

Although there is some evidence from longitudinal studies that decreases in physical activity during adolescence may result in increases in weight gain [15-18] the findings from this 4-year longitudinal study in a large population-based sample of adolescents do not confirm this. Therefore our findings did not support our hypothesis that a decrease in physical activity during adolescence would result in an increase in weight gain (i.e., BMI percentile) during this time. Other studies have also found that weight status and physical activity may not be inversely related during adolescence $[19,20]$ indicating that research in this area is equivocal and future research is needed to further investigate the association. These studies need to be adequately powered longitudinal studies with frequent objective measures of physical activity throughout adolescence.

We did not observe a consistent association between changes in physical activity and subsequent weight gain although an unexpected positive association was observed in the adolescents who reported the highest change in physical activity (i.e., more than 10 hours per week). Several reasons may explain this. First, weight status was determined using BMI criteria for children and adolescents. Although BMI has been shown to be a valid screening tool for weight status categories among adolescents, it is known to not accurately predict changes in body fat, especially during the adolescent growth period [29]. Perhaps these findings represent a change in body composition, not weight status per se. Research has shown that increased levels of physical activity during the pre-pubertal years leads to a decrease in the amount of body fat and increase in lean mass during the adolescent years [30]. The present study was unable to establish whether there were any changes in percentage of body fat over the study period, even if BMIderived weight status remained the same. Second, no information was collected on the adolescents' diet in the current study, therefore significant increases or decreases in energy intake over time were not known. It is possible that the changes in weight status could be due to a 
change in daily caloric consumption. Third, changes in time spent sedentary (such as the hours per day spent watching TV, playing video games, or using the computer) was also not accounted for in this study which could have contributed to the lack of an association between physical activity and weight status. Studies have reported that sedentary time during adolescence impacted weight status more so than physical activity [31,32] and that sedentary time during this period becomes more common and increases with increasing age [33]. Finally, a change in activity level of more than 10 hours per week is a substantial change and could be a result of the adolescent participating in a competitive sport one measurement year and not the next, or vice versa. The MPAQ assesses numerous aerobic activities, however, we do not know if the adolescent participated in the activity as part of an organized sports team. Being a part of an organized sports team one measurement year and not another year has the potential to change one's body composition and/or weight status substantially. To explore this possibility further, it is essential to have more robust methodology in both physical activity and body composition assessment.

In the adult literature researchers have proposed a stronger reverse association i.e., that increases in weight are associated with increases in physical inactivity [34-36]. Although this association has not yet been studied in children and adolescents, it may be that this is the case for the adolescents in this study as well. Future work in other longitudinal data in young people should address this issue of reverse causality in order to further disentangle the potentially complex relationship between physical activity and weight. However, one should be aware that the methodological issues of measurement error in the measures of weight and physical activity affects the conclusions when they are used as either the outcome or exposure [37].

This study had many strengths including the use of a valid and reliable adolescent physical activity questionnaire, a large and diverse sample of adolescents, and repeated annual assessments of physical activity and body composition measurements over four consecutive years. Physical activity and body composition (height and weight) were assessed annually over four years by a member of the research staff to ensure accuracy of the measurement. Despite these strengths, the study also had some limitations. The main exposure variable, physical activity, was measured via self-report. Although the MAQ is reported to be both valid and reliable in adolescents [26] self-report is a subjective measure with individual biases. An objective measure of physical activity (such as an accelerometer or pedometer) would have been preferable. Similarly, a more precise measure of body composition (i.e., waist circumference, percent body fat, skinfolds) would have been desirable. As our most significant findings are in the category of 10 hours per week or more of physical activity, there is the possibility that these adolescents were participating in an organized sport. Having a more objective measure of body composition, such as DEXA for example, would have given us a better estimate of their percent body fat and decreased the chances of our more athletic adolescents being misclassified on their BMI alone. As mentioned previously, we did not have access to data on some potentially confounding variables such as dietary and sedentary behaviour [38] although new evidence suggests that sedentary behaviour does not directly displace physical activity [39]. Maturation may be another variable to be taken into account, especially in this age group, but this data was not collected as part of the AICS. Although this study had data from 994 adolescents, a recent systematic review on this topic found that studies with greater than 1000 participants were more supportive in finding an inverse association between change in physical activity and change in adiposity [14]. It may therefore be that this study was underpowered to detect this association, although we did include multiple observations per participant in our analyses. Moreover, the relatively small effect estimates and lack of trend in the associations observed give some indication that a significant inverse association would probably also not have been detected in a larger sample of these adolescents. The data used for these analyses was collected 20 years ago, which could be considered a limitation. However, it is unlikely that the association between changes in physical activity and weight gain has changed over the decades. In addition, this data was collected in the same time period as the National Heart, Lung and Blood Institute's Growth and Health study, which previously has shown an inverse association between physical activity and BMI in adolescent girls [17]. Lastly, it is difficult to establish representativeness of the analyses sample to the wider population. However, the sample recruited into the AICS study came from a school district representative of other US school districts [26] and the random selection procedure of the students within the school district should ensure representativeness of the sample.

In conclusion, the results of the current study indicate that during this adolescent growth period the changes in BMI percentile are not explained by preceding changes in physical activity. We therefore believe that the association between changes in physical activity and body weight during adolescence remains unclear and requires further investigation. These longitudinal studies should include objective measures of a variety of health behaviours, such as physical activity, sedentary time and diet, and study their changes in relation to weight gain to elucidate the association between these variables. Furthermore, more precise measures of body composition (i.e., DEXA) need to be used to ensure proper assessment of the rapid gains in weight that naturally occur during the adolescent growth period, in particular the increase in muscle mass in boys and body fat in girls. A better understanding of the role of physical (in) activity in the development of obesity is needed in order to inform its prevention and treatment.

\section{Acknowledgements}

This paper is dedicated to the memory of Dr. Deborah Aaron.

\section{References}

1. Ogden CL, Carroll MD, Kit BK, Flegal KM (2014) Prevalence of childhood and adult obesity in the United States, 2011-2012. JAMA 311: 806-814.

2. Gurnani M, Birken C, Hamilton J (2015) Childhood Obesity: Causes, Consequences, and Management. Pediatr Clin North Am 62: 821-840.

3. Rocchini AP, Katch V, Anderson J, Hinderliter J, Becque D, et al. (1988) Blood pressure in obese adolescents: effect of weight loss. Pediatrics 82: 16-23.

4. Ferguson MA, Gutin B, Le NA, Karp W, Litaker M, et al. (1999) Effects of exercise training and its cessation on components of the insulin resistance syndrome in obese children. Int J Obes Relat Metab Disord 23: 889-895.

5. Kahle EB, Zipf WB, Lamb DR, Horswill CA, Ward KM (1996) Association between mild, routine exercise and improved insulin dynamics and glucose control in obese adolescents. Int J Sports Med 17: $1-6$.

6. Mallory GB Jr, Fiser DH, Jackson R (1989) Sleep-associated breathing disorders in morbidly obese children and adolescents. J Pediatr 115: 892-897.

7. Eisenberg ME, Neumark-Sztainer D, Story M (2003) Associations of weight-based teasing and emotional well-being among adolescents. Arch Pediatr Adolesc Med 157: 733-738. 
8. Parsons TJ, Power C, Logan S, Summerbell CD (1999) Childhood predictors of adult obesity: a systematic review. Int J Obes Relat Metab Disord 23 Suppl 8: S1-107.

9. Gutin B, Barbeau P, Owens S, Lemmon CR, Bauman M, et al. (2002) Effects of exercise intensity on cardiovascular fitness, total body composition, and visceral adiposity of obese adolescents. Am J Clin Nutr 75: 818-826.

10. Seidell JC, Cigolini M, Deslypere JP, Charzewska J, Ellsinger BM, et al. (1991) Body fat distribution in relation to physical activity and smoking habits in 38-year-old European men. The European Fat Distribution Study. Am J Epidemiol 133: 257-265.

11. Slattery ML, McDonald A, Bild DE, Caan BJ, Hilner JE, et al. (1992) Associations of body fat and its distribution with dietary intake, physica activity, alcohol, and smoking in blacks and whites. Am J Clin Nutr 55: 943-949.

12. Ross CE, Hayes D (1988) Exercise and psychologic well-being in the community. Am J Epidemiol 127: 762-771.

13. Stephens $\mathrm{T}$ (1988) Physical activity and mental health in the United States and Canada: evidence from four population surveys. Prev Med 17: 35-47.

14. Jimenez-Pavon D, Kelly J, Reilly JJ (2010) Associations between objectively measured habitual physical activity and adipostiy in children and adolescents: systematic review. Int J Pediatr Obes 5: 3-18.

15. Riddoch CJ, Leary SD, Ness AR, Blair SN, Deere K, et al. (2009) Prospective associations between objective measures of physical activity and fat mass in 12-14 year old children: the Avon Longitudinal Study of Parents and Children (ALSPAC). BMJ 339: b4544.

16. Fulton JE, Dai S, Steffen LM, Grunbaum JA, Shah SM, et al. (2009) Physical activity, energy intake, sedentary behavior, and adiposity in youth. Am J Prev Med 37: S40-49.

17. Kimm SY, Glynn NW, Obarzanek E, Kriska AM, Daniels SR, et al. (2005) Relation between the changes in physical activity and body-mass index during adolescence: a multicentre longitudinal study. Lancet 366: 301-307.

18. Raustorp A, Mattsson E, Svensson K, Ståhle A (2006) Physical activity, body composition and physical self-esteem: a 3-year follow-up study among adolescents in Sweden. Scand J Med Sci Sports 16: 258-266.

19. McMurray RG, Harrell JS, Creighton D, Wang Z, Bangdiwala SI (2008) Influence of physical activity on change in weight status as children become adolescents. Int J Pediatr Obes 3: 69-77.

20. Stevens J, Murray DM, Baggett CD, Elder JP, Lohman TG, et al. (2007) Objectively assessed associations between physical activity and body composition in middle-school girls: the Trial of Activity for Adolescent Girls. Am J Epidemiol 166: 1298-1305.

21. Kettaneh A, Oppert JM, Heude B, Deschamps V, Borys JM, et al. (2005) Changes in physical activity explain paradoxical relationship between baseline physical activity and adiposity changes in adolescent girls: the FLVS II study. Int J Obes (Lond) 29: 586-593.

22. LaPorte RE, Dearwater SR, Chang YF, Songer TJ, Aaron DJ, et al. (1995) Efficiency and accuracy of disease monitoring systems: application of capture-recapture methods to injury monitoring. Am J Epidemiol 142: 1069-1077.
23. Anderson R, Dearwater SR, Olsen T, Aaron DJ, Kriska AM, et al. (1994) The role of socioeconomic status and injury morbidity risk in adolescents. Arch Pediatr Adolesc Med 148: 245-249.

24. Center for Disease Control and Prevention. Healthy People 2010.

25. Kriska AM, Caspersen CJ (1997) A collection of physical activity questionnaires. Medicine Science Sports and Exercise pp: S79-S82.

26. Aaron DJ, Kriska AM, Dearwater SR, Cauley JA, Metz KF, et al. (1995) Reproducibility and validity of an epidemiologic questionnaire to assess past year physical activity in adolescents. Am J Epidemiol 142: 191-201.

27. (2005) Epi Info computer program. Version 3.3.2: Centers for Disease Control and Prevention.

28. Aaron DJ, Storti KL, Robertson RJ, Kriska AM, LaPorte RE (2002) Longitudinal study of the number and choice of leisure time physical activities from mid to late adolescence: implications for school curricula and community recreation programs. Arch Pediatr Adolesc Med 156: 1075-1080.

29. Pietrobelli A, Faith MS, Allison DB, Gallagher D, Chiumello G, et al. (1998) Body mass index as a measure of adiposity among children and adolescents: a validation study. J Pediatr 132: 204-210.

30. Moore LL, Gao D, Bradlee ML, Cupples LA, Sundarajan-Ramamurti A, et al. (2003) Does early physical activity predict body fat change throughout childhood? Prev Med 37: 10-17.

31. Gortmaker SL, Must A, Sobol AM, Peterson K, Colditz GA, et al. (1996) Television viewing as a cause of increasing obesity among children in the United States, 1986-1990. Arch Pediatr Adolesc Med 150: 356-362.

32. Andersen RE, Crespo CJ, Bartlett SJ, Cheskin LJ, Pratt M (1998) Relationship of physical activity and television watching with body weight and level of fatness among children: results from the Third National Health and Nutrition Examination Survey. JAMA 279: 938-942.

33. Brodersen NH, Steptoe A, Boniface DR, Wardle J (2007) Trends in physical activity and sedentary behaviour in adolescence: ethnic and socioeconomic differences. Br J Sports Med 41: 140-144.

34. Mortensen LH, Siegler IC, Barefoot JC, Grønbaek M, Sørensen TI (2006) Prospective associations between sedentary lifestyle and BMI in midlife. Obesity (Silver Spring) 14: 1462-1471.

35. Petersen L, Schnohr P, Sørensen TI (2004) Longitudinal study of the longterm relation between physical activity and obesity in adults. Int J Obes Relat Metab Disord 28: 105-112.

36. Bak H, Petersen L, Sørensen TI (2004) Physical activity in relation to development and maintenance of obesity in men with and without juvenile onset obesity. Int J Obes Relat Metab Disord 28: 99-104.

37. Wareham NJ, van Sluijs EM, Ekelund U (2005) Physical activity and obesity prevention: a review of the current evidence. Proc Nutr Soc 64: 229-247.

38. Hobbs M, Pearson N, Foster PJ, Biddle SJ (2014) Sedentary behaviour and diet across the lifespan: an updated systematic review. Br J Sports Med.

39. Pearson N, Braithwaite RE, Biddle SJ, van Sluijs EM, Atkin AJ (2014) Associations between sedentary behaviour and physical activity in children and adolescents: a meta-analysis. Obes Rev 15: 666-675. 